\title{
QUESTÕES DE GÊNERO, RACIALIZAÇÃO E CULTURA POLÍTICA NA DESVENTURADA REPÚBLICA: SANTO ANTONIO DE JESUS (BAHIA)
}

\author{
EDINELIA MARIA OLIVEIRA SOUZA \\ UNIVERSIDADE DO ESTADO DA BAHIA (UNEB)
}

\begin{abstract}
RESUMO: Este texto traz uma reflexão sobre relações de gênero, discriminação racial e cultura política no pós-abolição, a partir de um episódio conflituoso ocorrido na cidade de Santo Antonio de Jesus, recôncavo sul da Bahia. Trata-se de um crime de agressão física, envolvendo uma doméstica (vítima) e um comerciante local (acusado), cujo processo criminal - principal documento trabalhado aqui - destaca outros dois personagens centrais da trama (um comerciante alemão e um advogado), sinalizando toda uma complexidade de relações vividas naqueles primeiros tempos da República brasileira.
\end{abstract}

PALAVRAS-CHAVE: Gênero; Racialização; Pós-Abolição; Bahia.

ABSTRACT: This paper brings a reflection about gender relations, racism and political culture on the Brazilian post-abolition context, from a conflicting episode occurred in Santo Antonio de Jesus city, recôncavo sul region of Bahia. It was a crime with physical aggression, between a domestic woman worker as the victim, and a local merchant, which also involves a German merchant and a lawyer as two central actors, revealing a entirely complexity of human relations experienced in the beginnings of Brazilian Republican History.

KEYWORDS: Gender; Racialization; Post-abolition; Bahia. 
Era noite do dia 6 de junho de 1929, período em que ocorria o novenário dos festejos ao santo padroeiro de mesmo nome da cidade de Santo Antonio de Jesus, quando um grupo de senhores reunidos na casa comercial de Eufhrodisio Costa, mais conhecido como Lobo, começou a fofocar ${ }^{1}$ sobre os acontecimentos da cidade, dentre estes, o relacionamento existente entre a doméstica Felippa e o patrão Ricardo Grimminstein. Juvenal Diamantino de Carvalho que teria ido até a casa comercial para trocar uma bride ${ }^{2}$ comentava com João Elysio Galvão e Emyglio Marques sobre a viagem do alemão Ricardo Grimminstein à cidade da Bahia $^{3}$, alegando que este teria trazido muito dinheiro proveniente da venda de uma casa pertencente à sua esposa, na então cidade de Afonso Penna, atual Conceição do Almeida.

Embora estivesse acontecendo em um espaço público, aquela "palestra íntima" teria tido menor repercussão não fosse a curiosidade de Emyglio em relação à vida de Felippa, "ama e amásia" do alemão Ricardo. Ao responder ao questionamento de Emiglio, Juvenal demonstrava certa intimidade e interesse a respeito da vida da doméstica, dizendo que ela "estava no mesmo lugar, não como amásia, mas como ama, que de sargento passou a soldado raso" ${ }^{4}$. Naquele momento, Felippa, que se encontrava na vizinhança da venda onde se passava a conversa, ao ouvir a pronúncia do seu nome, dirigiu-se à porta do recinto para tomar satisfação, indagando "em que assunto estava o senhor Juvenal destratando de seu nome" ${ }^{\prime \prime}$. Embora os senhores envolvidos na conversa tenham negado que falavam da vida de Felippa, esta, ainda mais contrariada, afirmou que "é costume de quando se reunirem é somente para tratar de seu nome" "fosse embora e não ficasse procurando questões"'7. Felippa, então, retrucou e se referiu a Juvenal como "capadócio, moleque e canalha", afirmando que não se retiraria dali, ao tempo em que também ameaçou atirar uma garrafa nele.

\footnotetext{
${ }^{1}$ Segundo Nobert Ellias "A fofoca (...) não é um fenômeno independente. O que é digno dele depende das normas e crenças coletivas e das relações comunitárias". Para o autor, "O uso comum nos inclina a tomar 'fofocas' em especial, as informações mais ou menos depreciativas sobre terceiros, transmitidas por duas ou mais pessoas umas às outras". Mas "A fofoca, no entanto, sempre tem dois polos: aqueles que a circulam e aqueles sobre quem é circulada". (ELIAS, Nobert. Os estabelecidos e os outsiders: sociologia das relações de poder a partir de uma pequena comunidade. Rio de Janeiro: Jorge Zahar Ed., 2000, p. 121, 129 e 130).

${ }^{2} \mathrm{O}$ mesmo que brida - rédea; acessório usado para prender a cabeça do cavalo e, assim, o cavaleiro manter-se equilibrado e no controle do animal, ao segurá-lo com as mãos.

${ }^{3}$ Cidade da Bahia era como os moradores do interior se referiam e ainda hoje muitos se referem a Salvador - capital da Bahia.

${ }^{4}$ Depoimento de Juvenal Diamantino de Carvalho. Processo Criminal - 1929. Arquivo Público Municipal de Santo Antonio de Jesus.

${ }^{5}$ Depoimento de Felippa Salles. Processo Criminal - 1929. Arquivo Público Municipal de Santo Antonio de Jesus.

${ }^{6}$ Ibid.

7 Depoimento do acusado Juvenal Diamantino de Carvalho. Processo Criminal - 1929. Arquivo Público Municipal de Santo Antonio de Jesus.
} 
Em seguida, Juvenal revidou tratando-a de "cachorra", ao que a mesma interlocutora dissera que "cachorra tinha ele dentro de sua casa"8.

Naquele mesmo instante, Juvenal, munido de uma taca ${ }^{9}$, investiu contra Felippa, "resultando neste atrito sahir Felippa com alguns ferimentos no corpo $^{\prime 10}$. Agredida, a mesma teria saído à procura da autoridade policial quando, novamente, fora insultada com "nomes injuriosos" pronunciados por Juvenal.

O episódio ocorreu no ano de 1929, portanto, mais de três décadas após a abolição da escravidão e, exatamente, três décadas após o advento da República. Naquela conjuntura, a República brasileira vivia um turbilhão de acontecimentos no campo político, social e econômico, uma vez que a chamada política do café com leite, predominante durante toda essa primeira fase do regime republicano, experimentaria grandes abalos em seus alicerces, quando se ampliava o número de cidadãos descontentes, sobretudo, com o alto grau de poder concentrado entre as elites agrárias do Sudeste brasileiro.

Foi naquele contexto de tensas relações sociais e políticas que aconteceu o crime citado, cuja motivação teria sido o relacionamento amoroso entre a doméstica parda Maria Felippa Salles e o negociante alemão Ricardo Grimminstein. Tal crime, caracterizado por agressão física contra Felippa, fora cometido pelo também negociante Juvenal Diamantino de Carvalho, que apresentou como seu advogado de defesa o bacharel Mário de Castro Araújo.

De certo, o embate vivido na trama protagonizada por essas personagens não fosse tão incomum no Brasil de então. O processo criminal encontrado no empoeirado Arquivo Público do Município de Santo Antonio de Jesus permite-nos desvendar um conflito ocorrido no plano pessoal que sinaliza a existência de uma complexa rede de relações e significados forjados no cotidiano daquela localidade baiana. A leitura atenta do documento aponta uma intrincada rede vivida por indivíduos de diferentes posições hierárquicas que mantinham relações distintas naquela pequena cidade do recôncavo sul da Bahia, marcada por hierarquizações diversas, por disputas políticas e sociais nos primeiros tempos da República brasileira.

O conflito descrito acima originou a abertura do processo contra Juvenal, no qual a Promotoria Pública tomou por base o Artigo 305 do então Código Penal Brasileiro ${ }^{11}$, que destacava o crime de lesões corporais e prévia a prisão do criminoso por período de um a três anos. Como se pode notar, trata-se de uma zona de tensão, na qual estiveram envolvidos, além dos dois protagonistas, alguns outros moradores da cidade de Santo Antonio de Jesus. Felippa e Juvenal, indivíduos de posições hierárquicas distintas (status, sexo,

\footnotetext{
${ }^{8}$ Ibid.

${ }^{9} \mathrm{O}$ mesmo que chicote, cordel entrançado ou correia de couro, com cabo de madeira ou não, usado para incitar animais; açoite, azorrague, chibata.

${ }^{10}$ Depoimento da testemunha João Elysio Galvão. Processo Criminal - 1929. Arquivo Público Municipal de Santo Antonio de Jesus.

${ }^{11}$ No Código Penal Brasileiro de 1890, em seu art. 305 do Capítulo V - Das Lesões Corporais, consta: "Servir-se alguém, contra outrem, de instrumento aviltante no intuito de causar-lhe dôr physica e injuria-lo: Pena de prisão cellular por um a três anos".
} 
cor/raça) confrontaram-se no jogo das disputas cotidianas, das relações pessoais, de gênero ${ }^{12}$ e de poder, constituindo e reafirmando dimensões sociais significativas daquele contexto de "desventurada República", conforme palavras do advogado de defesa de Juvenal.

De um lado estava a empregada doméstica Felippa ${ }^{13}$, parda, natural do município de São Felipe, com 20 anos de idade ${ }^{14}$, mulher destemida, que não hesitou em confrontar-se com o grupo de senhores que a difamavam. Essa mulher "pintada com cores carregadas", "meretriz depravada", "rameira de ponta de rua", "diabólica", "infernal"15, ao se envolver afetivamente com o patrão branco, estrangeiro e casado, teria afrontado os valores morais predominantes não apenas naquela "cidade inerme e desarmada" ${ }^{16}$, mas na sociedade brasileira como um todo, fortemente marcada por hierarquizações, tanto do ponto de vista da condição social, como do ponto de vista da cor/raça e da relação de gênero. Logo, teria ela saído do "seu lugar" por duas vezes: primeiro, porque de ama passou a amásia de seu patrão branco; segundo, porque ousou revidar os insultos que recebera do negociante, denunciando-o à Justiça.

Destacamos aqui toda a complexidade que envolve as classificações de cor, desde o século XIX, onde o termo pardo era comumente associado ao conteúdo social ${ }^{17}$. Logo, há que se levar em consideração tanto a memória e as marcas da escravidão como as disputas por espaços de poder e cidadania elementos fundamentais na construção e/ou manutenção dessas identidades de cor -, quer fossem do ponto de vista das instituições que identificavam a cor dos cidadãos, ou do ponto de vista dos indivíduos que as acionavam.

12 Entre os vários trabalhos historiográficos que discutem relações de gênero, destacamos: REIS, Isabel Cristina Ferreira dos. "Relações de gênero no cotidiano de mulheres negras da Bahia oitocentista". In: XAVIER, Giovana; FARIAS, Juliana Barreto; GOMES, Flavio (Orgs.). Mulheres negras no Brasil escravista e do pós-emancipação. São Paulo: Selo Negro, 2012. Na mesma coletânea, ver REIS, Adriana Dantas. Mulheres afro-ascendentes na Bahia: gênero, cor e mobilidade social (1780-1830). Ver também SOARES, Cecilia. C. Moreira. Mulher negra na Bahia no século XIX. Salvador: Eduneb, 2006.

${ }^{13}$ De acordo com o censo de 1920, no município de Santo Antonio de Jesus em relação às ocupações, a população feminina estava distribuída da seguinte maneira: $44 \%$ no serviço de agricultura, criação, caça e pesca; $38 \%$ no serviço da indústria e $12 \%$ no serviço doméstico. Os demais foram incluídos na categoria outros serviços. (Disponível em: <http//biblioteca, ibge.gov.br >. Acesso em: 10 e 11 nov. 2009).

${ }^{14}$ Vasculhamos os registros de batismo de São Felipe que constam no familysearch.org e não encontramos nenhuma Felippa sendo batizada no ano de 1909, quando teria sido o seu nascimento. Para o ano de 1910 não há registros de batismo catalogado no site. Porém, em 1906 encontramos o registro de batismo de Felippa, com três anos de idade, sendo filha natural de Maria Ely Liberta e tendo como padrinhos Lucio Ferreira de Cerqueira e Maria Ignez de Cerqueira. Essa Felipa nasceu em 1903 e em 1929 estaria com 26 anos.

${ }^{15}$ Todas essas expressões desqualificadoras de Felippa foram utilizadas pelo bacharel Mário de Castro Araújo em suas argumentações para a defesa do acusado Juvenal. Processo Criminal 1929. Arquivo Público Municipal de Santo Antonio de Jesus.

${ }^{16}$ Trecho do discurso do bacharel Mário de Castro Araújo. Processo Criminal - 1929. Arquivo Público Municipal de Santo Antonio de Jesus.

${ }^{17}$ Ver MATTOS, Hebe. Das cores do silêncio: significados da liberdade no Brasil escravista. Rio de Janeiro: Arquivo Nacional, 1995 / Nova Fronteira, 1997. 
Do outro lado estava o negociante Juvenal, branco, natural do município de Feira de Santana, com 46 anos de idade, um "modelar pai de família", "homem trabalhador e honesto", "marido bom"18 que, aliado a tantas outras pessoas do seu séquito, talvez não visse com bons olhos o fato de aquela "meretriz depravada" ter saído da condição de ama para a condição de amásia do seu próprio patrão. Menos ainda podia acatar a sua reação, afrontando-o publicamente e remetendo as ofensas sofridas para a sua esposa.

Estaria Juvenal contrariado com o fato de aquela "atrevida" mulher ter se envolvido com seu possível concorrente, um próspero empreendedor estrangeiro que deixara esposa e filhos para viver a relação amorosa? Estava ele com ciúmes de Felippa? Embora sendo negociante naquela cidade, parece que Juvenal não se encontrava numa condição econômica tão próspera, diferentemente do que ocorria com o alemão Ricardo e isso já seria um bom motivo para aguçar a sua insatisfação diante da relação estabelecida entre o negociante estrangeiro e sua ama. Um indício para admitir tal situação seria o próprio discurso de defesa do advogado Mário Araújo, quando fez questão de salientar que os filhos do "homem trabalhador e honesto" não ficaram sem 0 leite porque ele não teria cobrado os devidos honorários.

Tudo indica que a atitude de Juvenal também traduzia certo ressentimento em relação à escolha feita por Felippa que, embora pudesse ser uma "rameira de ponta de rua", "uma alma mareada pela devassidão"19, afirmara insistentemente "nunca suspendi o babado da minha saia pra você" ${ }^{20}$, insinuando, portanto, que não teria se rendido às prováveis investidas do seu agressor.

A verdade é que a abertura do processo parece ter detonado um vespeiro de onde se espalharam rivalidades políticas e sociais, posições morais e racistas, enfim, ali eclodiram elementos e significados diversos da realidade vivida naquela localidade baiana, no contexto da sociedade republicana. Nesse caso, para além da troca de agressões entre um homem de certo prestígio social e uma mulher de moral tida como duvidosa, surpreende-se sinais outros da trama cotidiana reinventada pelos indivíduos na tessitura das relações constituídas em uma cidade do interior da Bahia, envolta nas disputas políticas, econômicas e sociais que caracterizavam as hierarquias de poder constituídas no pós-abolição, naqueles primeiros tempos da República brasileira, provavelmente agravadas pelo contexto de crise dos anos de 1920.

\footnotetext{
${ }^{18}$ Discurso do bacharel Mário de Castro Araújo. Processo Criminal - 1929. Arquivo Público Municipal de Santo Antonio de Jesus.

${ }^{19}$ Ibid.

20 Depoimento de Felippa Salles. Processo Criminal - 1929. Arquivo Público Municipal de Santo Antonio de Jesus.
} 
Sabe-se que durante toda a segunda metade do século XIX o Brasil recebeu grandes levas de imigrantes europeus que se dirigiram, sobretudo, para o centro-sul do País. Muitos outros se refugiaram também para 0 Norte/Nordeste no contexto do período entre guerras, quando a crise se abateu naquele continente. Na Bahia, ainda que em modestas proporções, a imigração também se fez presente: alemães, italianos, ingleses, espanhóis e alguns outros europeus inseriram-se em atividades econômicas diversas. Nesse contexto, as empresas de exportação de fumo do recôncavo baiano constituíram um dos ramos onde predominou a influência dos alemães, como era o caso de Ricardo Grimminstein, proprietário de armazém de fumo em Santo Antonio de Jesus.

A inserção dos imigrantes nos espaços econômicos e sociais locais/regionais, muitas vezes, despertava descontentamento por parte das velhas oligarquias, sobretudo, pelos comerciantes que disputavam esses espaços de poder, o que tornava ainda mais complexas as relações estabelecidas entre os indivíduos ${ }^{21}$. Não foi à toa que, conforme relata Isaías Alves, por ocasião da Segunda Guerra Mundial, o alemão Ricardo Grimminstein teve sua residência invadida e saqueada por pessoas cujos ânimos se exaltaram naquela cidade. O clima de hostilidade aos alemães devido ao contexto da guerra, aliado ao fato de que os tradicionais comerciantes foram gradativamente perdendo espaço para os investidores estrangeiros, certamente contribuíram para a expulsão do negociante alemão da cidade de Santo Antonio de Jesus. Dali ele teria saído escoltado pela polícia até a estação de trem que o conduziria para Salvador, onde as autoridades competentes da capital tomariam as devidas providências ${ }^{22}$.

Os depoimentos das testemunhas do caso em estudo, juntamente com o discurso do advogado de defesa de Juvenal, nos possibilitam analisar essa zona de tensão, que mais do que se imagina, assinala variantes das relações de poder presentes naquela conjuntura baiana. Notadamente, personagens coadjuvantes da cena, todas residentes em Santo Antonio de Jesus, constituíram as testemunhas arroladas no processo. Foram elas Emylio Francisco Marques, 41 anos, casado, natural da cidade de Arathuipe, alfabetizado e empregado no comércio; Eufhrodisio Costa, 22 anos, casado, artista, natural e residente em Santo Antonio de Jesus, que não sabia ler nem escrever; João Elysio Galvão, 50 anos, casado, natural e residente em Santo Antonio de Jesus, alfabetizado e empregado do comércio; e Hermínio Gonsalves de Almeida, 34 solteiro, natural do termo de Conceição do Almeida, alfabetizado, negociante.

\footnotetext{
${ }^{21} \mathrm{Em}$ estudo sobre o recôncavo sul, Ana Maria Carvalho dos S. Oliveira apurou que na segunda metade do século XIX havia 300 estrangeiros em Santo Antonio de Jesus, com uma população total de 9.654 habitantes em 1872, e um total 12.976 habitantes em 1892, verificando-se, assim, um aumento populacional de $26 \%$. É bom lembrar que a Vila de Santo Antonio tornou-se município em 1880 e passou à categoria de cidade em 1891, o que certamente contribuiu para esse aumento populacional na última década do século XIX. OLIVEIRA, Ana Maria Carvalho dos Santos. Recôncavo sul: terra, homens, economia e poder no século XIX. Salvador/Ba: Uneb, 2002.

${ }^{22}$ ALVES, Isaías. Matas do Sertão de Baixo. Rio de Janeiro: Reper Editora e Publicidade, 1967, p. 284-285.
} 
Como se pode perceber, eram cidadãos ocupantes de diferenciadas funções no urbano, que se reuniam nos estabelecimentos comerciais ou vendas - espaços muito presentes na composição daquele cenário social -, para tratar de assuntos variados do dia a dia, da cidade e da região.

O evento envolvendo Felippa e Juvenal assumiu proporções políticas, conforme se percebeu no processo instaurado pela Promotoria Pública e, ao que tudo indica, abalou o cotidiano de moradores e frequentadores da cidade. Muito astuciosamente e demonstrando larga erudição, o bacharel recémformado Mário de Castro Araújo - advogado de defesa do acusado Juvenal -, remeteria a contenda para o campo das divergências entre facções da política local, as quais justificariam o processo sofrido por aquele "homem trabalhador e honesto". Com tal discurso fazia crer que a acusação sofrida por Juvenal estava relacionada com "o desmando, a confusão, o terror e a anarchia espalhada por muitos dos tais senhores chefes políticos" ${ }^{\prime 23}$. Logo, aquilo tudo não passava de uma farsa montada para atingir um desafeto político, haja vista a posição de Juvenal contrária ao grupo político onde se incluíam o delegado e o seu chefe imediato, o intendente municipal.

Aliado ao argumento de perseguição política, o advogado de defesa recorreu ao viés da moralidade, procurando desqualificar a vítima que teria desrespeitado as famílias santantonienses no momento em que retrucou 0 xingamento do acusado, afirmando que cachorra ele teria "dentro de sua casa". Ainda nesse sentido, há, no discurso do bacharel, certa naturalização da agressão provocada pelo acusado que, "perdendo a estribeira de cavalheiro, fora da calma que lhe é habitual"24, surrou Felippa e a chamou de cachorra. Nesse caso, tal atitude não seria uma grande ofensa se comparada à "gravidade" da reação dela, que se utilizando de sua "linguagem de alcouce", própria das "almas mareadas pela devassidão", revidou o xingamento para a esposa de Juvenal, maculando a imagem da mulher virtuosa "casada nas leis dos homens e nas leis de Christo", mãe de "quatro filhinhos escrínios de peregrina inocência"25. De tal forma o advogado de defesa, ao tempo em que diabolizava a vítima Felippa, acentuava a imagem de mãe de família e mulher virtuosa à esposa de Juvenal, reforçando, assim, a visão dicotômica, pecadora/santa, que predominava em relação às mulheres, ao mesmo tempo em que defendia a vigente concepção de família.

Assim, ao afirmar que a "lama preferiu macular a neve", o advogado conceituava Felippa como a sujeira, a mulher "infernal" e "diabólica" que fora capaz de desfazer um lar. Logo, ao remeter os xingamentos recebidos para uma mulher virtuosa, estaria Felippa cometendo um crime contra a honra da família formada pela união civil e religiosa conforme as normas estabelecidas. Aliás, é importante lembrar que nos jornais que circulavam na época, eram recorrentes

${ }^{23}$ Discurso do advogado Mário de Castro Araújo em defesa de Juvenal Diamantino Carvalho. Processo Criminal - 1929. Arquivo Público Municipal de Santo Antonio de Jesus.

${ }^{24}$ Ibid.

${ }^{25}$ Ibid. 
matérias evidenciando a boa educação da mulher, como pode ser visto em um texto publicado no Palladio em 1921, de autoria de Almeida Garret:

A educação embrandece pelles duras, amacia mãos ásperas, dá graça e doçura a olhos de pouca luz, faz interessante a face pallida e affáveis os lábios descorados, põe a bondade de coração na fronte que não é alva, torna elegante o corpo que não é airoso, amável o que não é lindo, engraçado o que não é formoso ${ }^{26}$.

A postura de Felippa, contrária ao que se esperava de uma mulher educada e com "bondade de coração", tornava-a desmerecedora de credibilidade e, por certo, de justiça. Assim, na visão do advogado de defesa de Juvenal, o processo era "mais um atentado ao pudor das famílias, do que tudo" ${ }^{\prime 27}$.

Assumindo, portanto, uma clara posição política, social e cultural pautada nos padrões morais vigentes, nos códigos de conduta dominantes e no racismo científico, o bacharel investiu na ideia de que o acusado seria uma vítima da ignorância e dos desmandos presentes naquela sociedade acentuada pelos antagonismos mandonismo/subordinação, moralidade/imoralidade, ordem/desordem, que, enfim, se tornariam suficientes para isentar da condenação o distinto negociante Juvenal, cuja patente de Capitão teria sido reduzida "a ossos de borboleta". Juvenal, nascido em 1883, portanto apenas seis anos antes da proclamação da República no Brasil, talvez tivesse herdado de seu pai a patente de capitão ainda durante o império, quando o título tinha grande significado social e político.

O discurso moralista, ressentido e racista do jovem bacharel Mário de Castro Araújo, em certa medida, se relaciona à sua própria trajetória. Filho do Dr. Antonio José de Araújo, juiz de Direito do município de Maracás, e da Sra. Guilhermina de Castro Araújo, Mário pertencia a uma tradicional família estabelecida em Santo Antonio de Jesus. Formado em 1920 pela Faculdade de Direito da Bahia, fora recebido no mês de dezembro daquele ano na referida cidade por grande quantidade de pessoas de "todas as classes sociais", tendo ainda a participação ilustre das duas philarmônicas locais, a Amantes da Lyra e a Carlos Gomes "que romperam em marcha enternecedoras, saudando a chegada do futuroso moço" ${ }^{\prime 28}$. Entre os discursos de felicitação ao bacharel, ocorridos na estação ferroviária da cidade, quando da sua chegada, destacouse o pronunciamento do professor Viriato Lobo, que o saudou entre "os ecos agudos de palmas numerosas", advertindo-o sobre os atrativos da política e ainda sobre o incontestável quarto poder da imprensa, que,

\footnotetext{
${ }^{26}$ Jornal Palladio, 1921. Santo Antonio de Jesus - Bahia. Grifo nosso.

27 Trecho do discurso do advogado Mário de Castro Araújo em defesa de Juvenal Diamantino Carvalho. Processo Criminal - 1929. Arquivo Público Municipal de Santo Antonio de Jesus.

${ }^{28}$ Jornal Palladio, 1920. Santo Antonio de Jesus - Bahia.
} 
nos paízes regidos por libertina Constituição, como o nosso, avassalado hoje pelo sórdido interesse, pela baixa política e pelo despeito inconfessável, pode receber-vos em seu seio em cuja tenda a inflexibilidade do vosso carácter e a intuição clara, nítida, do bem público traçarão para ella uma nova trajetória, iluminada pela honra, pela probidade e pelo patriotismo ${ }^{29}$.

$\mathrm{Na}$ ocasião, o bacharel retribuiu as felicitações, externando agradecimentos por meio de um pronunciamento ao auditório em "testemunho vibrante de sua fibra intelectual"30. Em seguida, rumaram todos "em busca da granja 'São Benedito', aprazível moradia da família"31, local que mais tarde tornou-se um dos maiores bairros da cidade. Ali toda a família Araújo o recebera em clima de festa e "copioso almoço íntimo", seguido de um chá dançante, que contou com a presença de "muitas senhoritas e cavalheiros nos salões da pitoresca vivenda" a bailar ao som da philarmônica Carlos Gomes até às três horas da madrugada ${ }^{32}$.

Não resta dúvida de que a chegada do bacharel na cidade de Santo Antonio de Jesus foi um dia de grande festa, com homenagens ao jovem seguidor dos passos de seu progenitor. Mas entre aquele dia festivo e a sua apresentação como advogado de defesa de Juvenal em 1929, o doutor Mário teria vivido dias difíceis e de desespero que o afastaram da vida forense. Tratase de um crime em que ele se envolveu logo depois de ter retornado à cidade natal. Foi em 2 de fevereiro de 1922 que o bacharel protagonizou um episódio que marcaria de forma definitiva a sua trajetória. Um desentendimento com o dentista Amphilophio Pedral provocara a morte deste por meio de disparos proferidos pela arma de fogo do bacharel, quando este se encontrava em luta corporal com o cunhado do dentista.

$\mathrm{Na}$ "tarde sombria" daquele dia de Iemanjá estava o bacharel em casa, lendo o jornal Estado de São Paulo, quando suas irmãs (Zilda, Iara e Aracy), chegando de uma aula de prendas, entraram em casa "com olhos rasos d'água", acompanhadas de sua mãe, "que também mostrava a aflição no rosto" e ignorando-o encaminharam-se para a sala de visitas e puseram-se a comentar o ocorrido. Ao se aproximar da sala, o doutor Mário ouvira a conversa de suas irmãs que comentavam sobre ofensas e zombarias praticadas pela família Pedral, quando estas passavam em frente à sua residência. De acordo com seu relato, toda a confusão entre as duas famílias teria se iniciado no início de 1921 quando o Jornal Palladio anunciara um concurso para eleger a moça mais bonita da cidade de Santo Antonio de Jesus e sua irmã Zilda "teve o infortúnio de conquistar votação superior aos merecimentos physicos e espirituais ${ }^{\prime 33}$. Tudo

\footnotetext{
${ }^{29}$ Trechos do discurso do professor Viriato Lobo por ocasião da recepção ao jovem bacharel na cidade, publicado no Jornal Palladio. Grifo nosso.

${ }^{30}$ Ibid.

${ }^{31}$ Jornal Palladio, 1920. Santo Antonio de Jesus - Bahia.

32 Ibid.

${ }^{33}$ Informações extraídas do discurso que o advogado Mário de Araújo Castro elaborou para a sua própria defesa
} 
não passaria, então, de um grande insulto, que motivara fofocas e zombarias. Contrariado com o que estava acontecendo, o bacharel se armou e foi tomar satisfações com a família do dentista Amphilophio na casa deste, quando entrou em luta com o seu cunhado, ocasionando o disparo da arma de fogo que atingiu mortalmente o dentista, levando-o a óbito ${ }^{34}$.

Depois do acontecimento, o jovem bacharel, assustado e com medo, fugira para a cidade de Maracás, mais tarde entregando-se à justiça. Mário de Araújo foi julgado em 1928, quando apresentou um intenso e inflamado discurso em sua própria defesa e, ao que tudo indica, foi declarado inocente, uma vez que um ano depois estava ele assumindo a defesa de Juvenal. Em sua própria defesa, apelou para a honradez da família, sobretudo citando o caráter e a carreira do pai, que seria seu grande incentivador, reafirmando, também, a tese da busca de entendimento e do "ataque traiçoeiro" que sofrera dos seus algozes, o que teria provocado o mortal tiro disparado pela sua arma, quando procurava se defender do ataque ${ }^{35}$.

Deduz-se a partir da narrativa de Mário de Araújo que, por trás desse episódio envolvendo duas famílias de posse e prestígio social naquela cidade, encontravam-se disputas de poder, apadrinhamento, lealdades traídas, provocação e vingança. Elementos esses que despertariam no jovem e elogiado bacharel a iniciativa de tomar satisfações em nome de sua família, o que o levou a ficar frente a frente com o crime e, mais que isso, a se tornar um criminoso, passando, assim, de profissional habilitado à defesa em juízo para a condição de réu.

A narrativa bastante erudita, escrita em sua própria defesa, aponta uma diversidade de elementos que provocam reflexões sobre as relações cotidianas e o jogo de poder mantidos entre as famílias de posse naquela localidade. Reporta também às sociabilidades e os interesses políticos que envolviam um variado grupo de pessoas que, naqueles primeiros tempos republicanos, se posicionavam ora nas instituições de poder, ora na oposição, visando obter certas vantagens e satisfazer interesses pessoais ou de grupo.

A resumida trajetória do bacharel Mário de Araújo é de fundamental importância para a compreensão do seu posicionamento frente ao processo que envolveu a ama Felippa e o negociante Juvenal, nove anos após receber seu diploma. Suas argumentações para a defesa do agressor Juvenal encontravam total ressonância com o discurso do professor Viriato Lobo que, na ocasião em que o bacharel chegara de volta à cidade natal, demonstrava insatisfação em relação à vigente República. Assim, não resta dúvida de que o doutor Mário, tal qual o professor Viriato, integrava um grupo de representantes da elite baiana descontente com os rumos que a sociedade brasileira, em geral, e as instituições representativas do poder local, em particular, teriam tomado naquelas décadas de República na Bahia e no Brasil.

\footnotetext{
${ }^{34}$ Ibid.

${ }^{35}$ Informações extraídas do discurso que o advogado Mário de Araújo Castro elaborou para a sua própria defesa.
} 
Foi justamente no final da década de 1920 que se acentuou o denominado bacharelismo em substituição ao coronelismo, embora essas forças não se constituíssem como antagônicas, mas como complementares ${ }^{36}$. Ao que parece, o advogado Mário de Araújo simpatizava com esse movimento e, por meio dos discursos de defesa inscritos nos autos dos dois processos, aproveitou para fortalecer as críticas ao mandonismo, demonstrando ressentimento e insatisfação com a República e, consequentemente, assumindo uma posição contrária à chefia política do município de Santo Antonio de Jesus que, naquele momento, encontrava-se em mãos de adversários seus e de sua família.

Ao trazer à tona essa face da trajetória do bacharel Mário de Araújo nossa intenção foi mesmo traçar um paralelo entre as duas situações expostas. Fica claro que toda a experiência vivida pelo advogado em relação ao conflito e ao demorado processo criminal que sofreu influenciaria as bases de seu discurso na defesa de Juvenal.

A agressão física que Juvenal imprimiu contra Felippa, conforme atestada no laudo do corpo de delito anexado ao processo, teve papel secundário na argumentação do bacharel, que a encarou como um ato "estrictamente necessário à sua defesa". Incrível é que essa agressão denominada por ele de "ataque imediato" não fora presenciada por nenhuma das testemunhas nomeadas, que alegaram terem ido, naquele exato momento, prestar socorro à senhora do dono da venda que foi tomada por uma crise nervosa. Por outro lado, os depoimentos reforçavam terem visto "a queixosa com uma garrafa na mão, preparada, pronta, para executar o que dissera", reafirmando, portanto, que 0 acusado "foi atacado e defendeu-se"37. A testemunha Hermínio Gonsalves, por exemplo, afirmou ter ouvido várias pessoas falarem do atrevimento de Felippa que "xinga a família do senhor Juvenal e ainda quer partir-Ihe a cara com a garrafa", ao que ele comentara "a gente pra encontrar com o precipício não precisa sahir de casa" ${ }^{38}$. Ora, as testemunhas pertenciam ao rol de amizades do senhor Juvenal e nada mais compreensível que, de uma forma ou de outra, elas tenham reforçado o argumento da legítima defesa do acusado.

\footnotetext{
${ }^{36}$ SAMPAIO, Consuelo. Os partidos políticos da Bahia na Primeira República: uma política de acomodação. $2^{\text {a }}$ ed. Salvador: EDUFBA, 1999, p. 164.

37 Trecho do discurso do advogado Mário em que o mesmo recorre aos depoimentos das testemunhas. Processo Criminal - 1929. Arquivo Público Municipal de Santo Antonio de Jesus.

38 Depoimento da testemunha Hermínio Gonsalves. Processo Criminal - 1929. Arquivo Público Municipal de Santo Antonio de Jesus.
} 
Aliás, o laudo do corpo de delito também é questionado pelo advogado Mário de Araújo ao alegar que não fora feito por um profissional preparado para a função, embora houvesse cidadãos aptos na cidade, inclusive o próprio intendente Rosalvo Fonseca, formado em Medicina. Contudo, diante das provas reunidas no processo, associadas à própria confissão do réu sobre a agressão física, o juiz Juvenal da Silva julgou procedente a denúncia contra Juvenal Diamantino de Carvalho e, por ser o crime afiançável, arbitrou fiança provisória de (1:000\$.000) um conto de reis.

Valores como honra e moralidade motivaram o bacharel Mário de Araújo a tomar satisfação dos insultos que teria sofrido sua família, quando da exposição de sua irmã às zombarias e fofocas. Já no que diz respeito à desqualificação e à agressão sofridas por Felippa, seriam justificadas, pois ela própria teria atraído e provocado o crime já que, além de "pintada com cores carregadas", não seria uma mulher de bom comportamento social. Nesse caso, somente em uma República de "libertina Constituição", poderia se admitir o fato de uma mulher de moral e conduta tidas como duvidosas ter o direito de exigir da Justiça punição para um homem de bem que a agredira fisicamente ao agir em sua legítima defesa.

Munido de argumentos em que buscava defender certo código de honra masculina e familiar, sinalizando, ainda, uma postura discriminatória racial e social em relação à vítima de agressão, o bacharel Mário assumia uma posição que deixava clara a junção entre o pessoal e político. Desse modo, toda a linguagem envolta na trama nos permite abstrair um universo de valores, comportamentos e costumes que tendiam a normalizar e normatizar aquela sociedade pós-escravista e republicana.

Fica também evidente a posição do bacharel em relação às autoridades legais do município de Santo Antonio de Jesus. Não resta dúvida de que no jogo de poder oligárquico eram os interesses políticos que determinavam as nomeações de tais autoridades, na maioria das vezes, revelando-se incompetentes no exercício de suas funções. Dessa forma, faria algum sentido a frustração do bacharel com a República brasileira que "pobre e desventurada", compunha-se de maus representantes, como o delegado "espiga, pipocas" que "não tem a maior noção do que vem a ser moderação, lei, justiça e direito" e que tem a "cabeça descansada na arbitrariedade e o pé esmagando, insolente a liberdade" já que abriu o inquérito "e não contente ainda a mando de seu chefe ${ }^{\prime \prime 39}$ - no caso, o intendente municipal - prendeu aquele homem trabalhador que agira em sua própria defesa. Portanto, aquela "República desventurada" se contrapunha à ideia de "uma cidade que se diz civilizada, que tem Caixa Rural, Prédio Escolar e luz elétrica", onde se agiu "contra os fóros desta terra" ao "pôr o accusado incommunicável, sem direito a uma palavra amiga a um signal de conforto e confiança, no duro captiveiro da injustiça" ${ }^{\prime \prime 0}$.

\footnotetext{
39 Trechos do discurso do advogado Mário de Castro Araújo na defesa de Juvenal. Processo Criminal - 1929. Arquivo Público Municipal de Santo Antonio de Jesus.

${ }^{40}$ Ibid.
} 
Nesse sentido, para o doutor Mário, o processo contra Juvenal incompatibilizava com a sublime serenidade da Justiça. De tal forma, o mal do delegado viria do "analphabetismo que nos empolga, assombroso", e como "não sabe escrever", também não poderia "apreciar o mérito de uma pergunta ou resposta" ${ }^{41}$, pronunciada em depoimento. O delegado seria, portanto, uma criatura "de volição desmantelada pela vontade desgovernada de um homem a quem elle, lá na sua crendice chucra, chama de chefe e obedece numa humildade ridícula de monge decahido e torturado" ${ }^{\prime 42}$.

Fica evidente a forte crítica à figura do delegado, provavelmente de pouca intimidade com a leitura e a escrita, indicado ao cargo pelo intendente devido ao seu prestígio local e às relações de compromisso e lealdade com ele que, além de ser o representante maior do poder político municipal, ainda era fazendeiro e médico naquela cidade. Essa possível obediência do delegado em relação ao seu chefe político sinaliza dimensões do mandonismo e da subserviência que garantiriam o acordo estabelecido entre ambos para a manutenção do equilíbrio político municipal, de forma que, quando necessário fosse, poderia estar incluída a perseguição aos adversários ${ }^{43}$.

Conforme afirmou Sampaio, nesse período "o setor policial, apesar de submetido a rigorosa centralização, também não poderia escapar à influência dos chefes políticos municipais". Logo, o delegado constituía "peça coercitiva indispensável no processo eleitoral" e, portanto, "ao atender aos interesses da elite política local, ia também ao encontro dos anseios do Executivo". As nomeações "eram feitas depois de prévio entendimento do Secretário de Polícia com os chefes políticos, que indicavam os nomes de amigos que pudessem garantir-lhes controle da situação local" ${ }^{44}$. Era, portanto, nesse quadro que estava inserido o delegado Temístocles Fonseca Almeida, que seria ainda parente consanguíneo do então intendente Rosalvo Fonseca, o que reforçaria a relação de confiança e compromisso entre ambos.

Tratava-se, portanto, de um contexto baseado em um sistema de compromissos, de troca de favores e proveitos entre representantes do poder público e do poder privado. Naquela conjuntura a obtenção de certos ganhos não se dava apenas no jogo das trocas econômicas, mas, sobretudo nos apadrinhamentos, nas lealdades e nos compromissos que alimentavam hierarquias de poder e proteção. Foi nesse jogo que se cruzaram as histórias da doméstica Felippa, do alemão Ricardo, do comerciante Juvenal e do advogado Mário de Araújo, além de tantos outros indivíduos que, naquele momento, vivenciavam e constituíam o cotidiano da cidade de Santo Antonio de Jesus.

\footnotetext{
${ }^{41}$ Ibid.

${ }^{42}$ Ibid.

42 LEAL. Vitor Nunes. Coronelismo, enxada e voto. São Paulo: Alfa-Omega, 1975, p. 61.

${ }^{43}$ SAMPAIO. Op. cit., p. 162.
} 
O crime de agressão física cometido pelo comerciante Juvenal contra a doméstica Felippa, para além de possibilitar uma análise das tramas constituídas naquela sociedade de pós-escravidão e de primeiros tempos da República no município de Santo Antonio de Jesus, deixa evidente que, aos olhos de representantes dos setores dominantes, alguns indivíduos estavam ocupando lugares sociais que não deveriam ser os seus. Sem dúvida, esse foi o caso de Felippa, uma mulher pobre e parda que se envolveu afetivamente com o patrão branco, rico e estrangeiro, contrariando, assim, os valores predominantes naquela estrutura social, onde o racismo se propagava, quer seja no plano científico ou nas práticas cotidianas, no sentido de manter a demarcação das hierarquias raciais e sociais.

\section{Sobre a autora}

Edinelia Maria Oliveira Souza é doutora em História Social pela Universidade Federal do Rio de Janeiro (2012). Graduada em História pela Universidade do Estado da Bahia (1994). Especialista em Metodologia e Didática do Ensino Superior pela Universidade Católica do Salvador (1996). Mestre em História Social pela Pontifícia Universidade Católica de São Paulo (1999). Professora Adjunta da Graduação em História do DCH (Campus I/Uneb, na área de Teoria da História e Historiografia), e do Programa de Pós-Graduação em História Regional e Local no DCH (Campus V/Uneb). Membro da Diretoria do GT Nacional da Emancipações e Pós-Abolição (Anpuh). E-mail: edisouza7@hotmail.com.

Artigo recebido em 29 de janeiro de 2016.

Aprovado 31 de maio em 2016. 